\title{
KARAKTERISTIK ALTERASI DAN MINERALISASI EMAS PADA ZONA OKSIDASI DI DAERAH PANGAPIT, KABUPATEN SAMBAS, PROVINSI KALIMANTAN BARAT
}

\section{CHARACTERISTICS OF ALTERATION AND GOLD MINERALIZATION IN OXIDATION ZONE IN PANGAPIT, SAMBAS REGENCY, WEST KALIMANTAN PROVINCE}

\author{
Reza Fahmi ${ }^{1}$, Hartaja Muhamad Hatta W. ${ }^{2}$, dan Bambang Priadi ${ }^{1}$ \\ 1)Jurusan Teknik Geologi, Fakultas IImu dan Teknologi Kebumian, \\ Institut Teknologi Bandung \\ 2) Pusat Sumber Daya Mineral, Batubara dan Panas Bumi, Badan Geologi \\ rezafahmi14010@gmail.com
}

\begin{abstract}
ABSTRAK
Penelitian dilakukan di Dusun Pangapit, Desa Madak, Kabupaten Sambas, Provinsi Kalimantan Barat. Daerah tersebut memiliki tambang emas yang dikelola oleh masyarakat sekitar. Daerah di sekitar tambang telah mengalami oksidasi intensif yang ditandai oleh kondisi lapangan yang berwarna kemerahan dan banyaknya mineral oksida besi. Penelitian dilakukan guna mengetahui karakter dari alterasi dan mineralisasi di sekitar tambang dengan menggunakan metode analisis petrografi, mineragrafi, spektra dan geokimia.
\end{abstract}

Zona alterasi di daerah penelitian terdiri dari tiga zona, yaitu kaolinit, serisit-ilit dan klorit-epidotkalsit. Alterasi di daerah penelitian terjadi dalam dua tahap, tahap pertama terjadi setelah Eosen dan sebelum Pliosen, sementara tahap kedua terjadi setelah Pliosen-Pleistosen. Alterasi pertama ter-overprint sebagian oleh alterasi kedua.

Mineralisasi emas di daerah penelitian berupa urat dengan arah umum baratlaut-tenggara yang terdiri dari mineral kuarsa, hematit, goetit, pirolusit, pirit, dan kalkopirit. Emas pada mineralisasi primer berasosiasi sedang dengan unsur $\mathrm{Pb}$. Mineralisasi primer terpusat pada daerah tambang rakyat Pangapit di baratlaut Bukit Batubelah dengan hostrock tuf dan batulempung. Mineralisasi primer terjadi bersamaan dengan terjadinya alterasi pertama.

Kata kunci: Mineralisasi, Emas, Alterasi, Geokimia, Zona Oksida

\section{ABSTRACT}

Pangapit is located atSambas Regency, West Kalimantan. This district has a gold mine that managed by local residents. Area around mine is an oxidized zone. Research was held to find out the characteristics of alteration and mineralization around the mine by using petrographic, mineragraphy, spectra and geochemistry analysis.

Research area has three kind of alteration zones: kaolinite, serisite-illite, and chlorite-epidotecalcite. There are at least two stage of alteration occured in research area. First one occurred after Eocene and before Pliocene, mean while second alteration occured after PliocenePleistocene. Second alteration was superimposed on first alteration.

Gold mineralization in research area occured in the form of vein with north-west trend that consist of quartz, hematite, goethite, pyrolusite, pyrite, chalcopyrite. Gold in primary mineralization is moderately associated with $\mathrm{Pb}$. This mineralization occured in Pangapit mine, northwest of Batubelah Hill with tuff hostrock. Primary mineralization happened in the same time as the first alteration.

Keywords: Mineralizaton, Gold, Alteration, Geochemistry, Oxide Zone 


\section{PENDAHULUAN}

Kalimantan Barat terkenal sebagai daerah penghasil emas sejak abad ke 18 (Gunter, 2011). Salah satu daerah yang banyak memiliki tambang emas di Kalimantan Barat adalah Kabupaten Sambas. Proses penambangan emas di Sambas umumnya dilakukan oleh warga sekitar dalam skala kecil dengan cara tradisional (Anonim, 2014). Banyaknya kegiatan penambangan emas dalam skala kecil oleh rakyat di daerah Sambas belum dilakukan pendataan oleh pemerintah maupun dilakukan penelitian mengenai karakteristiknya. Oleh karena itu dibutuhkan adanya penelitian mengenai karakteristik alterasi hidrotermal dan mineralisasi emas pada zona oksidasi di salah satu daerah di Sambas yaitu Pangapit untuk mengetahui karakterisitik yang sesungguhnya dari cebakan mineral logam emas di tambang rakyat tersebut.

Penelitian dilakukan di daerah Pangapit yang terletak di Desa Madak, Kabupaten Sambas, Provinsi Kalimantan Barat, pada koordinat $109^{\circ} 19^{\prime} 35,6^{\prime \prime}$ BT-109 $22^{\prime} 59,8^{\prime \prime}$ BT dan $1^{\circ} 11^{\prime} 57,40^{\prime \prime}$ LU-1'15'09,11 LU. Area kerja terletak kurang lebih $100 \mathrm{~km}$ di utara Pontianak dan dapat dicapai melalui jalur darat dengan waktu tempuh kurang lebih enam jam. Penelitian dikhususkan pada zona oksidasi yang terpusat di sekitar tambang rakyat Pangapit. Zona ini dicirikan oleh warna kemerahan, kondisi lapuk, dan kehadiran mineral oksida besi yang melimpah.

\section{GEOLOGI REGIONAL DAERAH PENELITIAN}

Daerah Sambas memiliki enam satuan fisiografi (Thorp dkk, 1990 dalam Rusmana dan Pieters, 1993) yaitu zona pantai, dataran aluvial, undak pasir putih, perbukitan bergelombang lemah, perbukitan terjal terisolasi dan perbukitan bergelombang kuat. Daerah penelitian termasuk dalam zona perbukitan bergelombang lemah yang dicirikan oleh perbukitan dengan ketinggian yang tidak terlalu tinggi (sekitar $100 \mathrm{~m} \mathrm{dpl)} \mathrm{dan} \mathrm{lereng}$ yang tidak terlalu curam.

Stratigrafi regional daerah penelitian dibagi menjadi sembilan satuan (Rusmana dan Pieters, 1993), yaitu Formasi Seminis, Batuan Gunung Api Sekadau, Kelompok Bengkayang, Kelompok Serabang, Formasi Pedawan, Intrusi Granit Pueh, Batupasir Kayan, Intrusi Sintang dan Batuan Gunung Api Niut. Menurut peta geologi regional oleh Rusmana dan Pieters (1993), di daerah penelitian terdapat dua satuan geologi yaitu Formasi Seminis dan Intrusi Sintang. Formasi Seminis terdiri dari meta sedimen berumur Permian sedangkan Intrusi Sintang terdiri dari intrusi intermediet berumur Oligosen-Miosen.

Struktur regional di daerah Sambas secara umum memiliki tiga arah utama, yaitu baratlaut, timurlaut dan utara-timurlaut (Rusmana dan Pieters, 1993), khusus di daerah penelitian berarah baratlaut. Menurut Rusmana dan Pieters (1993), struktur dengan arah baratlaut ini terbentuk pada Zaman Kapur akibat aktivitas Subduksi Lupar yang terletak di Kalimantan Utara.

\section{GEOLOGI DAERAH PENELITIAN}

Secara umum daerah penelitian memiliki topografi bergelombang lemah yang dicirikan oleh kemiringan lereng berkisar antara 2\% s.d. 7\% (Van Zuidam, 1983). Daerah penelitian berupa dataran denudasional struktur lipatan menurut klasifikasi Brahmantyo dan Bandono (2006). Terdapat dua punggungan homoklin di daerah utara dan selatan daerah penelitian dengan kelurusan berarah baratlaut yang diinterpretasi terbentuk akibat kontrol struktur regional. Selain itu terdapat satu bukit lava di daerah penelitian. Aliran sungai di daerah penelitian memiliki pola dendritik dan rektangular yang mengindikasikan bahwa daerah penelitian memiliki litologi homogen dan dikontrol oleh struktur sesar.

Daerah penelitian memiliki tiga satuan batuan, yaitu Satuan Batulempung yang 
berumur Permian-Trias, Satuan Tuf yang berumur Eosen Akhir dan Satuan Basal yang berumur Pliosen-Pleistosen.

Terdapat dua struktur geologi yang berkembang di daerah penelitian yaitu antiklin dan sesar mendatar mengiri. Antiklin di daerah penelitian memiliki sumbu lipatan berarah barat-timur yang diinterpretasikan berumur Kapur. Sesar mendatar mengiri memiliki arah utaraselatan yang diinterpretasikan berumur Eosen.

\section{METODE}

Metode yang digunakan dalam penelitian ini meliputi pemetaan geologi, pengambilan conto batuan, analisis petrografi, analisis mineragrafi, analisis spektra dan analisis geokimia.

Pemetaan geologi dilakukan dengan memetakan singkapan batuan dan mem- plotnya kedalam peta. Aspek utama yang diperhatikan dalam pemetaan geologi yaitu penyebaran litologi dan struktur geologi. Pada saat pemetaan juga dilakukan pengambilan conto batuan untuk kemudian di analisis di laboratorium.

Analisis petrografi dilakukan dengan mengamati sayatan tipis dari conto batuan di bawah mikroskop polarisasi. Analisis ini dilakukan guna mengidentifikasi jenis batuan, jenis alterasi dan paragenesa alterasi. Analisis petrografi dilakukan pada 10 conto batuan.

Analisis mineragrafi dilakukan dengan mengamati sayatan poles dari conto batuan dibawah mikroskop pantul. Analisis ini dilakukan untuk mengetahui kandungan mineral logam pada urat serta paragenesisnya. Analisis mineragrafi dilakukan terhadap tujuh conto urat logam oksida dan urat kuarsa yang mengandung mineral opak.

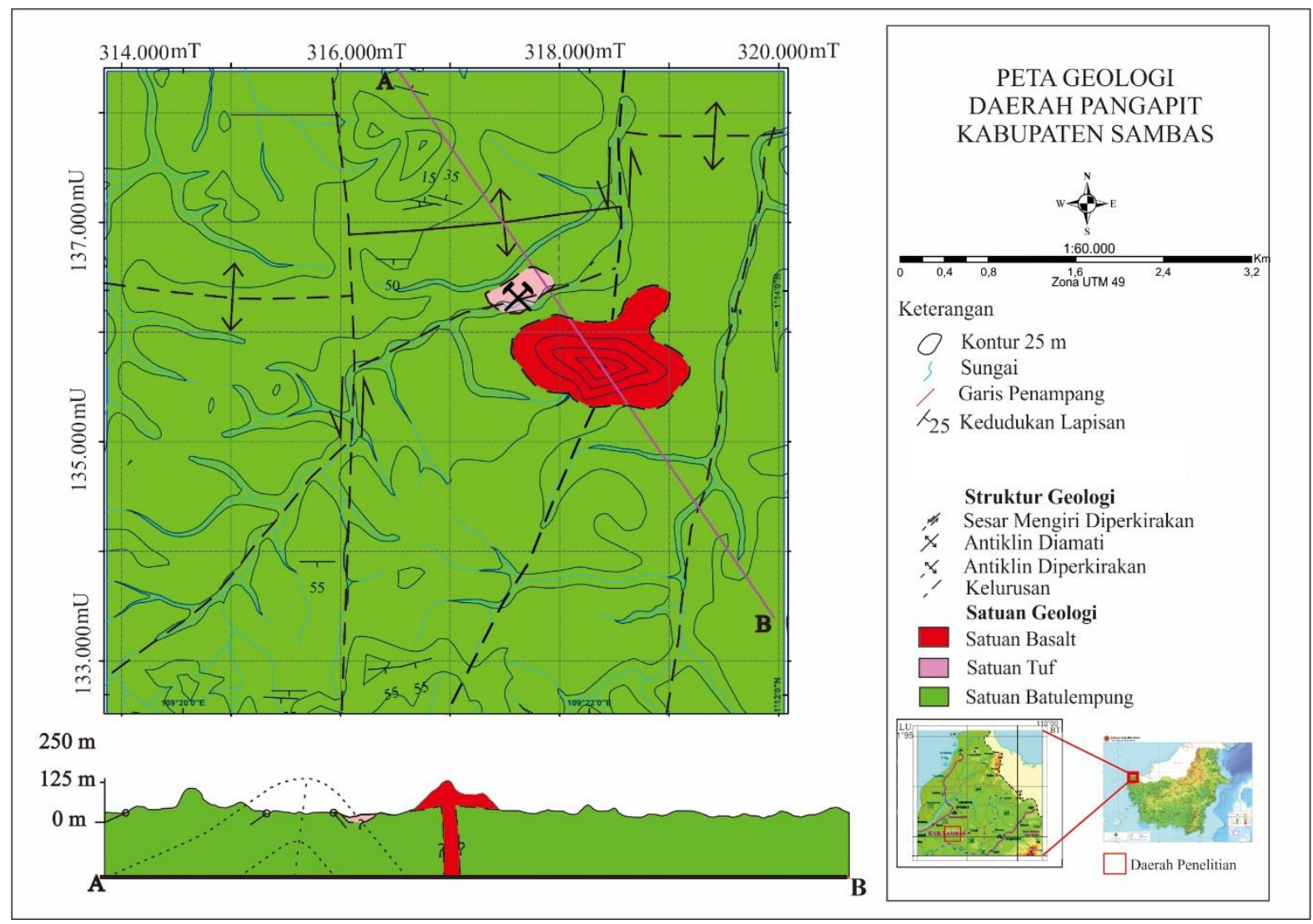

Gambar 1. Peta geologi daerah penelitian 
Analisis spektra dilakukan dengan bantuan alat PIMA (Portable Infrared Mineral Analyzer) di Pusat Sumber Daya Mineral, Batubara dan Panas Bumi. Conto batuan dipapar sinar inframerah, kemudian panjang gelombang hasil pantulannya dibaca untuk menentukan jenis mineral lempung yang dikandung oleh conto batuan. Analisis ini dilakukan untuk mengetahui jenis mineral lempung yang dapat digunakan untuk mengetahui jenis alterasi di daerah penelitian. Analisis spektra dilakukan terhadap 70 conto batuan.

Data geokimia yang digunakan didapatkan dengan melakukan uji AAS (Atomic Absorption Spectometry) terhadap 76 conto batuan yang menghasilkan kadar unsur $\mathrm{Au}, \mathrm{Ag}, \mathrm{Cu}, \mathrm{Pb}, \mathrm{Zn}$, As dan Sb. Uji AAS dilakukan di Laboratorium Pusat Sumber Daya Mineral, Batubara dan Panas Bumi. Data geokimia yang berasal dari conto batuan ini kemudian diolah dengan metode statistik dengan tujuan mengetahui unsur apa saja yang berasosiasi dengan emas pada mineralisasi primer di daerah penelitian. Penentuan asosiasi unsur dilakukan dengan menggunakan metode statistik Spearman (Weir, 2018).

\section{HASIL DAN ANALISIS ALTERASI DAERAH PENELITIAN}

Analisis petrografi dan spektra menunjukan bahwa daerah penelitian memiliki tiga jenis zona alterasi, yaitu zona kaolinit, zona serisit-ilit dan zona epidot-klorit-kalsit.

Zona kaolinit tersebar di seluruh daerah penelitan. Di lapangan, zona ini dicirikan oleh kondisi batuan yang lunak dan bewarna putih hingga keunguan (Gambar 2). Mineral sekunder yang hadir pada zona ini didominasi oleh kaolinit dengan sedikit diaspor, montmorilonit dan dikit. Kehadiran mineral-mineral tersebut menandakan bahwa zona ini terbentuk pada kondisi cenderung asam dan suhu rendah (Corbett dan Leach, 1998). Suhu pembentukan zona alterasi dapat diketahui dengan melihat tabel suhu pembentukan mineral (Tabel 1) oleh Morrison (1997). Zona ini terbentuk pada suhu sekitar $140^{\circ} \mathrm{C}$ hingga $230^{\circ} \mathrm{C}$.

Zona kaolinit telah mengubah batuan asalnya dengan intensitas tinggi sehingga batuan asalnya sulit untuk diidentifikasi. Pengamatan petrografi menunjukkan bahwa mineral lempung telah mengganti lebih dari $75 \%$ mineral asli batuan. Dari pengamatan sebaran litologi daerah penelitian diketahui bahwa zona ini mengubah Satuan Batulempung dan Satuan Tuf.

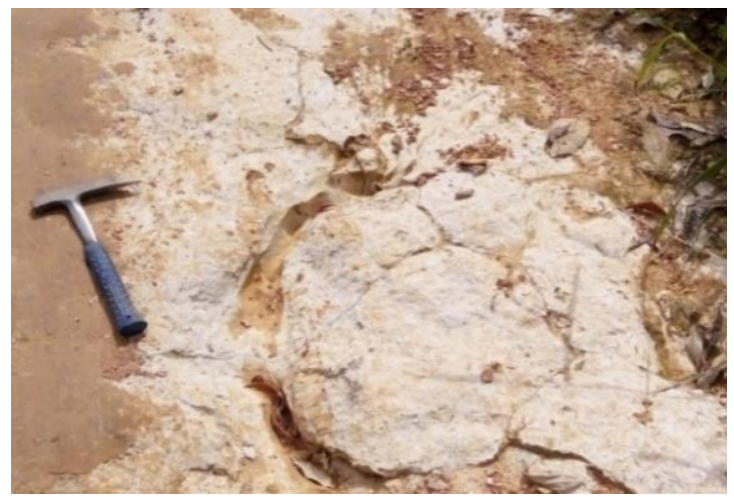

Gambar 2. Singkapan batuan teralterasi kaolinit di tepi jalan di selatan daerah penelitian

Zona klorit-epidot-kalsit secara umum terpusat di Bukit Batubelah, dan sebagian kecil juga ditemukan dalam jumlah sedikit di tempat lain. Zona ini mengubah batuan asal berupa basal dengan intensitas sedang yang ditandai oleh kadar mineral sekunder yang terdiri dari klorit, epidot dan kalsit berkisar antara $25 \%$ s.d. $75 \%$ (Morrison, 1997). Zona ini dicirikan oleh kenampakan batuan yang berwarna kehijauan. Kehadiran kumpulan mineral klorit, epidot dan kalsit menunjukan bahwa zona ini terbentuk pada kondisi netral (Corbett dan Leach, 1998). Suhu pembentukan zona alterasi dapat diketahui dengan melihat tabel suhu pembentukan mineral (Tabel 2) oleh Morrison (1997). Diperkirakan zona ini terbentuk pada suhu $>200^{\circ} \mathrm{C}$.

Zona serisit-ilit tersebar secara tidak merata pada daerah penelitian dan terpusat di beberapa titik, yaitu di tambang rakyat Pangapit, Bukit Kanyi dan Bukit 
Praja Sekadau sehingga diduga penyebaran zona ini tidak dikontrol oleh struktur utama daerah penelitian. Kemungkinan zona ini dikontrol oleh struktur minor yang tidak terpetakan, sehingga tersebar dalam bentuk jendelajendela kecil. Kehadiran mineral serisit dan illit menandakan bahwa zona ini terbentuk pada kondisi netral (Corbett dan Leach, 1998). Suhu pembentukan zona alterasi dapat diketahui dengan melihat tabel suhu pembentukan mineral (Tabel 3) oleh Morisson (1997). Diperkirakan zona ini terbentuk pada suhu $260^{\circ} \mathrm{C}$ hingga $320^{\circ} \mathrm{C}$. Berdasarkan pengamatan batuan sekitar dan letak zona serisit-ilit menunjukkan bahwa batuan asal yang diubah oleh zona ini adalah batulempung dan tuf.

Zona oksidasi yang terpusat di sekitar tambang rakyat Pangapit secara umum mengalami alterasi kaolinit dan serisit-ilit. Batuan pada zona ini telah terubah menjadi lempung dengan warna kemerahan hingga keunguan. Warna tersebut disebabkan oleh oksidasi intensif.

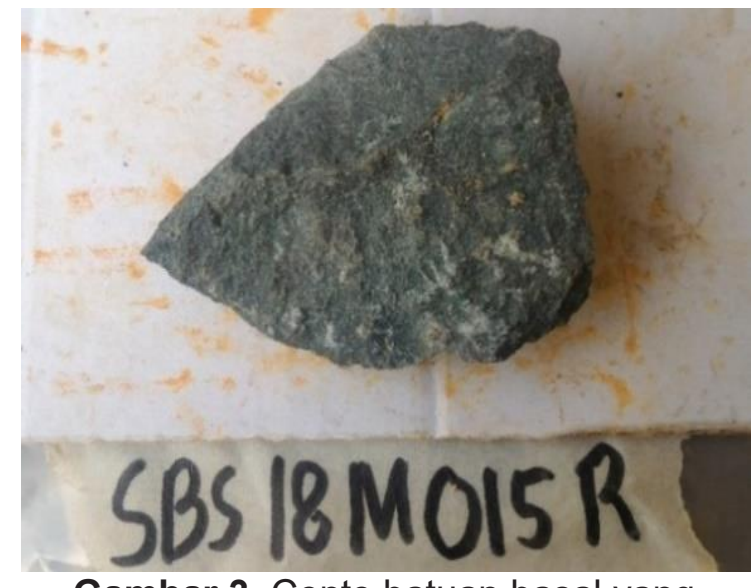

Gambar 3. Conto batuan basal yang teralterasi klorit-epidot-kalsit

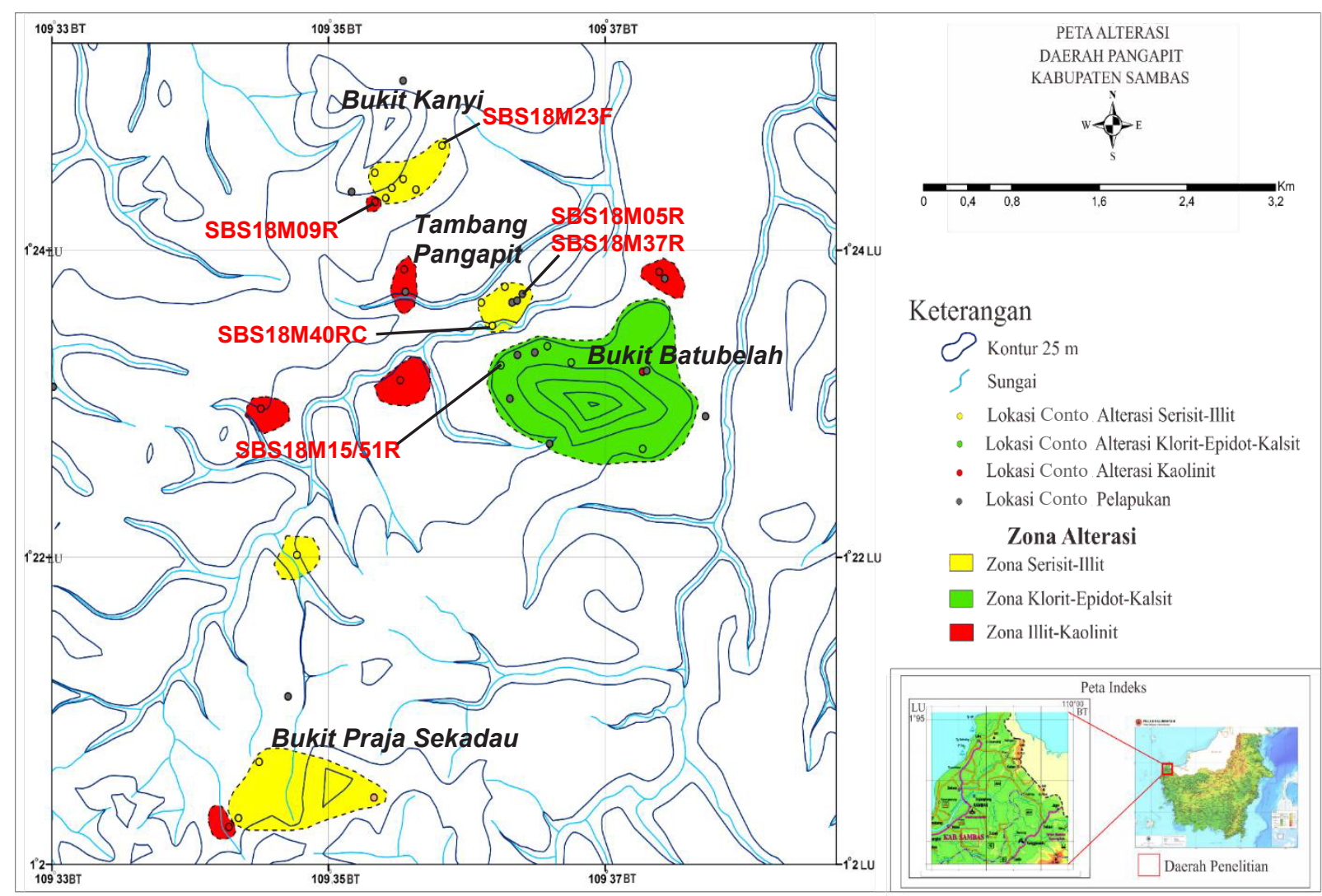

Gambar 4. Peta alterasi daerah penelitian 


\section{MAKALAH ILMIAH}

Tabel 1. Suhu pembentukan Zona Alterasi Kaolinit (Morrison, 1997)

\begin{tabular}{|c|c|c|c|}
\hline \multirow[b]{2}{*}{ Mineral } & \multicolumn{3}{|c|}{ Suhu } \\
\hline & 100 & 200 & 300 \\
\hline \multicolumn{4}{|l|}{ Kaolinit } \\
\hline \multicolumn{4}{|l|}{ Diaspor } \\
\hline Dikit & & ------ & \\
\hline Halloysit & 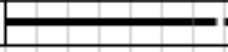 & 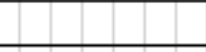 & \\
\hline
\end{tabular}

Tabel 2. Suhu pembentukan Zona Alterasi Klorit-Epidot-Kalsit Morrison, 1997)

\begin{tabular}{|c|c|c|c|}
\hline \multirow[b]{2}{*}{ Mineral } & \multicolumn{3}{|c|}{ Suhu } \\
\hline & 100 & 200 & 300 \\
\hline Klorit & -ーーーーー & & \\
\hline Epidot & \begin{tabular}{|l|l|l|} 
& & \\
\end{tabular} & & $---=$ \\
\hline Kalsit & & & \\
\hline
\end{tabular}

Tabel 3. Suhu pembentukan Zona Serisit-llit (Morrison, 1997)

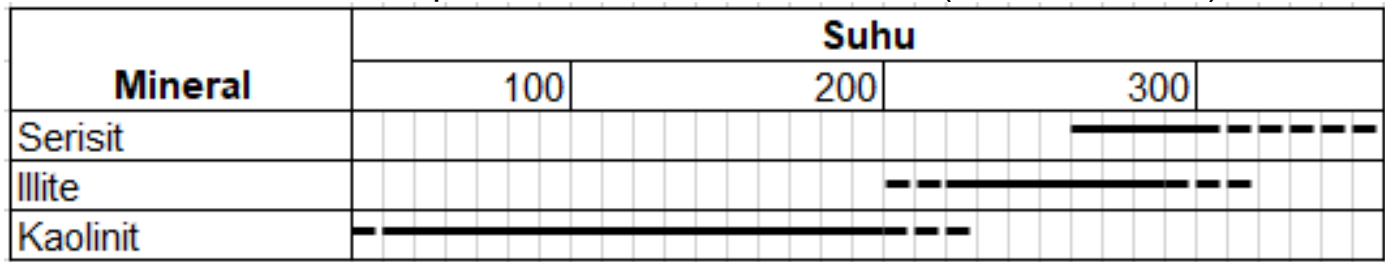

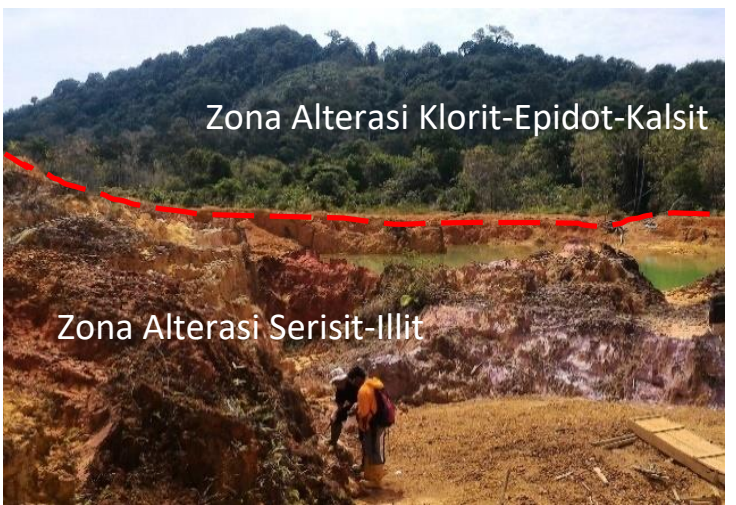

Gambar 5. Kenampakan zona oksidasi di tambang rakyat Pangapit

Paragenesa zona alterasi dapat diketahui dengan mengamati hubungan antar mineral sekunder pada sayatan tipis. Pengamatan terhadap sayatan tipis menunjukkan bahwa setiap zona alterasi saling mengganti satu sama lain. Sebagai contoh pada Gambar 6 tampak bahwa zona alterasi klorit-epidot-kalsit yang diwakili oleh mineral klorit mengubah zona serisit-ilit yang diwakili oleh mineral serisit sedangkan pada Gambar 7 tampak dari pengamatan petrografi bahwa zona serisitilit yang diwakili oleh mineral serisit mengubah zona klorit-epidot-kalsit yang diwakili oleh klorit. Pengamatan petrografi juga menunjukkan bahwa zona serisit-ilit dan kaolinit saling mengubah satu sama lain. Gambar 8 merupakan pengamatan petrografi yang menunjukkan adanya mineral lempung yang mewakili zona kaolinit mengubah mineral serisit yang mewakili zona serisit-ilit, sementara Gambar 9 menunjukkan hal yang sebaliknya, ada mineral serisit yang mengubah mineral lempung. Zona alterasi klorit-epidot-kalsit juga diketahui memiliki hubungan saling mengubah dengan zona alterasi kaolinit. Gambar 9 menunjukkan adanya klorit yang mengubah mineral lempung. 


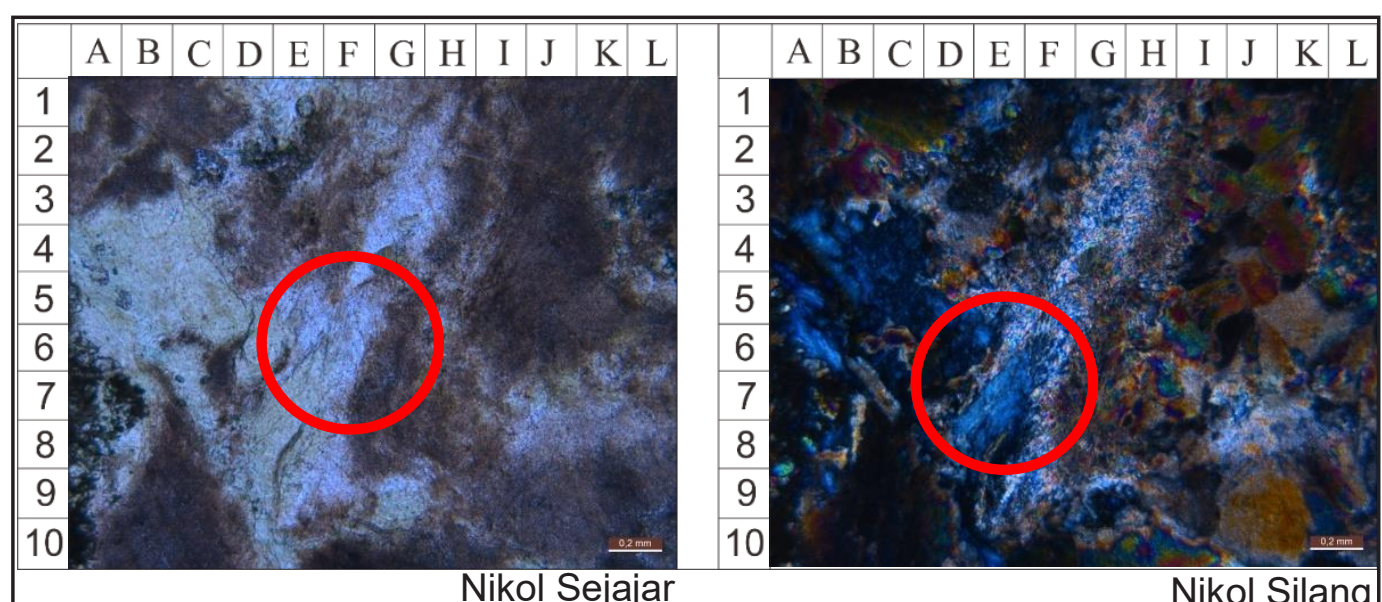

Gambar 6. Klorit memotong serisit (E6) pada sayatan tipis conto SBS18M051R

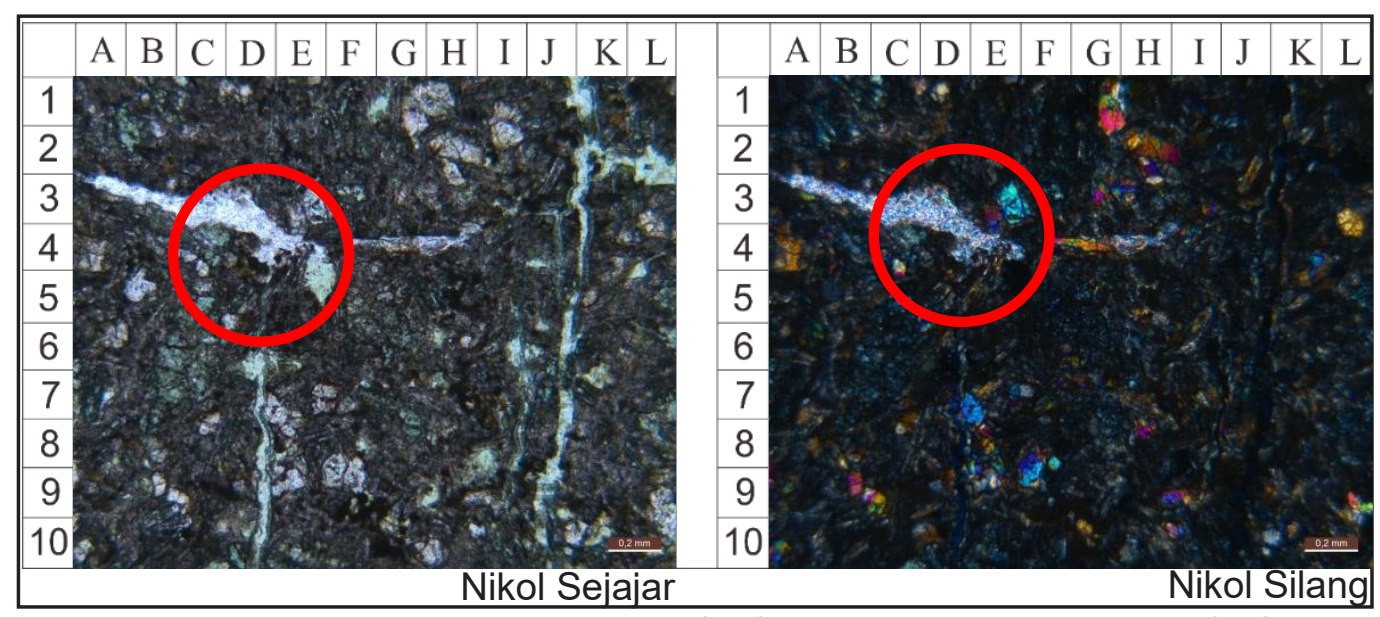

Gambar 7. Urat serisit memotong urat klorit (D4) pada sayatan tipis conto SBS18M051R
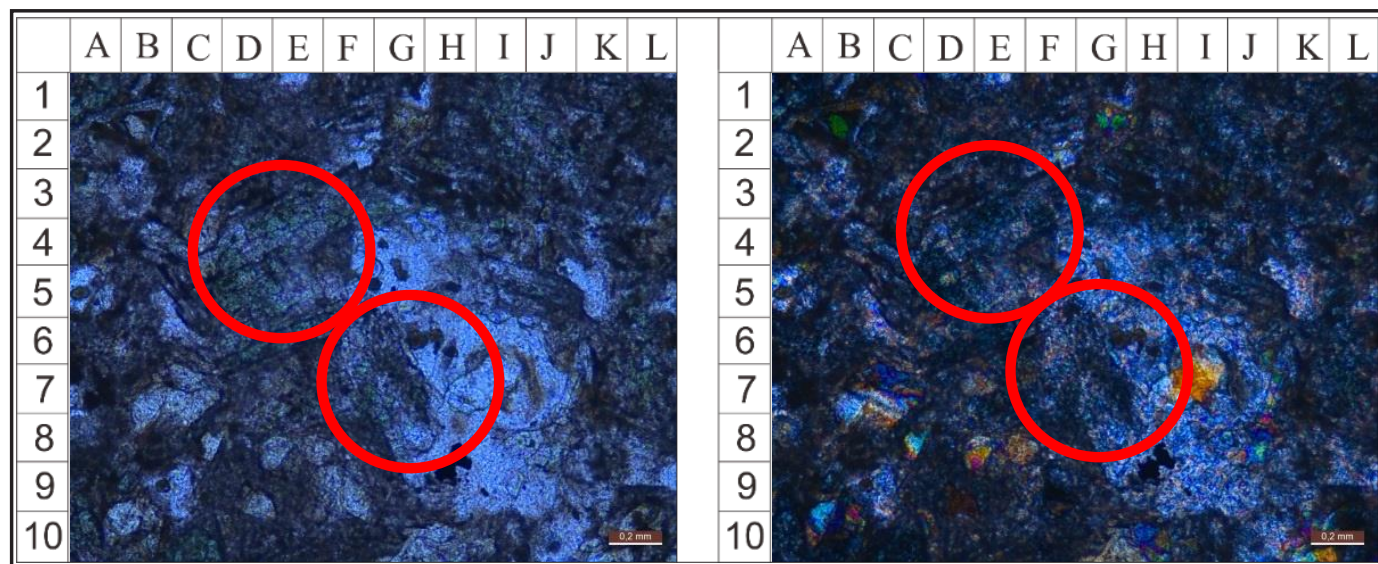

Nikol Sejajar

Nikol Silang

Gambar 8. Serisit memotong klorit (E5) dan mineral lempung memotong serisit (G7) pada sayatan tipis conto SBS18M051R 


\section{MAKALAH ILMIAH}

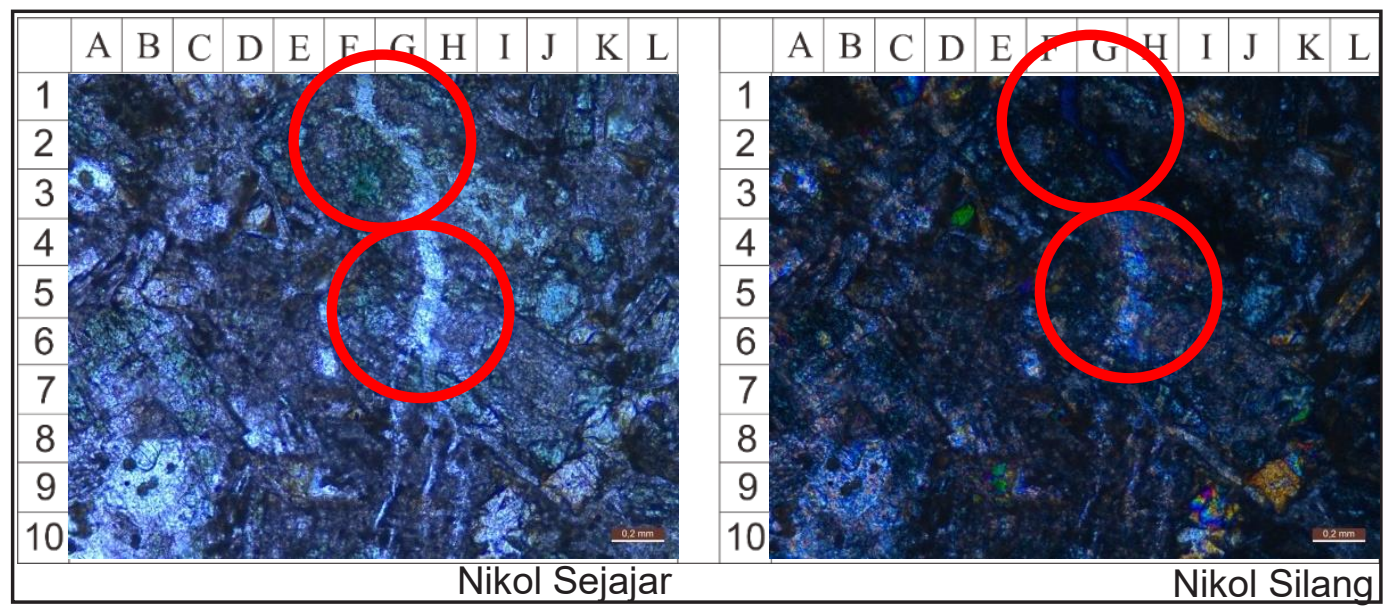

Gambar 9. Serisit memotong mineral lempung (G6)

dan klorit memotong mineral lempung (G3) pada sayatan tipis conto SBS18M051R

Adanya hubungan saling memotong antar semua zona alterasi menunjukkan bahwa kemungkinan alterasi terjadi dalam beberapa tahap. Penyelidikan di lapangan menemukan bahwa ada batuan teralterasi yang mengalami mineralisasi yang ditandai oleh hadirnya banyak pirit (contohnya di Tambang Pangapit) dan ada juga batuan teralterasi yang tidak mengalami mineralisasi (contohnya di Bukit Batubelah.) Kemungkinan alterasi terjadi dalam dua tahap dan setiap tahap terdiri dari zona alterasi kaolinit, zona serisit-illit dan klorit-epidot-kalsit.

Waktu pembentukan zona alterasi dapat diketahui secara relatif dengan cara melihat satuan batuan yang diubah oleh zona alterasi. Zona kaolinit diketahui mengubah Satuan Batulempung dan Satuan Tuf sehingga dapat diinterpretasi zona ini terbentuk setelah kedua satuan ini terbentuk yaitu setelah Eosen. Zona serisit juga mengubah Satuan Tuf dan Satuan Batulempung sehingga dapat diinterpretasi bahwa zona ini terbentuk pada waktu yang relatif sama. Zona klorit-epidot-kalsit mengubah satuan basal sehingga dapat diinterpretasi zona ini terbentuk setelah Pliosen-Pleistosen. Dengan melihat umur relatif dari batuan yang teralterasi, diketahui bahwa alterasi tahap pertama yang terdiri dari zona kaolinit, zona serisitillit dan zona klorit-epidot-kalsit terjadi pasca-Eosen dan alterasi tahap kedua yang juga terdiri dari zona kaolinit, zona serisit-illit dan zona klorit-epidot-kalsit terjadi pasca-Pleistosen. Di mana batuan yang teralterasi setelah Eosen mengalami mineralisasi sedangkan batuan yang tidak teralterasi terjadi setelah Pleistosen.

\section{MINERALISASI DAERAH PENELITIAN}

Mineralisasi emas di daerah penelitian terpusat di tambang rakyat Pangapit, baratlaut dari Bukit Batubelah. Mineralisasi emas ditemukan berasosiasi dengan urat kuarsa dan mineral oksida di dalam batuan induk tuf dan batulempung. Di lapangan mineralisasi emas ini dibuktikan dengan hasil pendulangan dari batuan yang ditumbuk (Gambar 10).

Urat kuarsa memiliki tekstur sisir (comb) yang terbentuk akibat proses pengisian rongga kosong. Secara umum urat memiliki arah baratlaut seperti yang ditunjukkan oleh diagram mawar pada Gambar 11c. Pengamatan megaskopis menunjukkan bahwa mineral oksida pada urat merupakan hematit yang dicirikan oleh warna hitam kemerahan, kilap submetallicdull, kekerasan < 6,5, gores bewarna merah kecoklatan.

Pengamatan mineragrafi yang dilakukan terhadap tujuh conto urat menunjukkan bahwa urat mengandung mineral oksida hematit, goetit, pirolusit dengan sedikit mineral sulfida pirit dan kalkopirit seperti yang ditunjukkan oleh Tabel 4. Secara 
umum mineral opak pada urat didominasi oleh mineral oksida seperti hematit, goetit dan pirolusit. Mineral sulfida berupa pirit dan kalkopirit pada urat hanya ditemukan dalam jumlah yang sedikit dengan ukuran kecil dan bentuk tidak beraturan. Dan yang perlu dicatat dari hasil pengamatan sayatan poles, tidak ditemui adanya emas di urat kuarsa yang didapat dari daerah penelitian. Selain itu data geokimia juga menunjukkan bahwa kadar emas dari conto urat kuarsa tidak tinggi. Conto yang memiliki kadar emas tinggi berupa batuan samping di sekitar urat kuarsa. Sehingga diinterpretasikan bahwa emas sudah didistribusikan ke batuan samping. Ini dibuktikan dari hasil dulang (Gambar 10) dari batuan disekitar urat yang menunjukkan kehadiran butir emas, tetapi yang cukup menarik hasil data geokimia untuk unsur emas pada batuan samping tersebut tidak berkorelasi positif dengan keterdapatan butir emas.

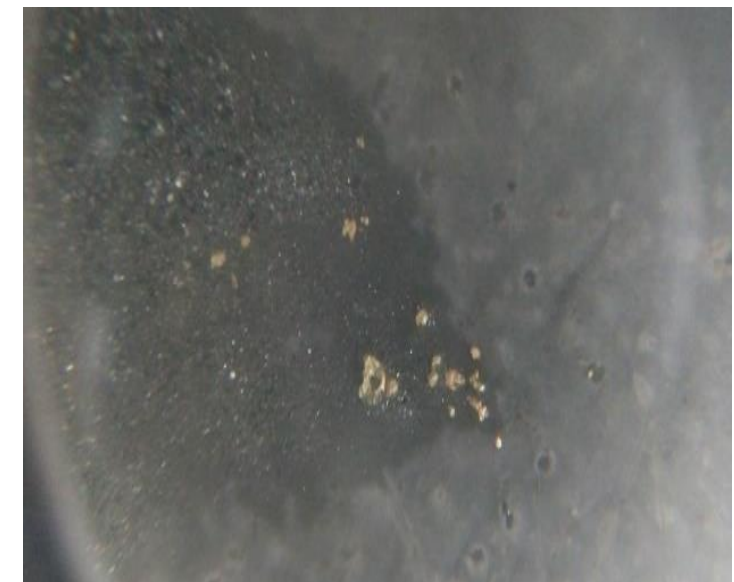

Gambar 10. Butiran emas hasil dulang (panning concentrate)

Tambang rakyat Pangapit telah mengalami proses pelapukan dan oksidasi yang intensif. Kemungkinan mineral sulfida yang ada di urat telah terubah menjadi mineral oksida karena proses oksidasi sehingga mineral sulfida hanya tersisa sedikit di daerah penelitian.

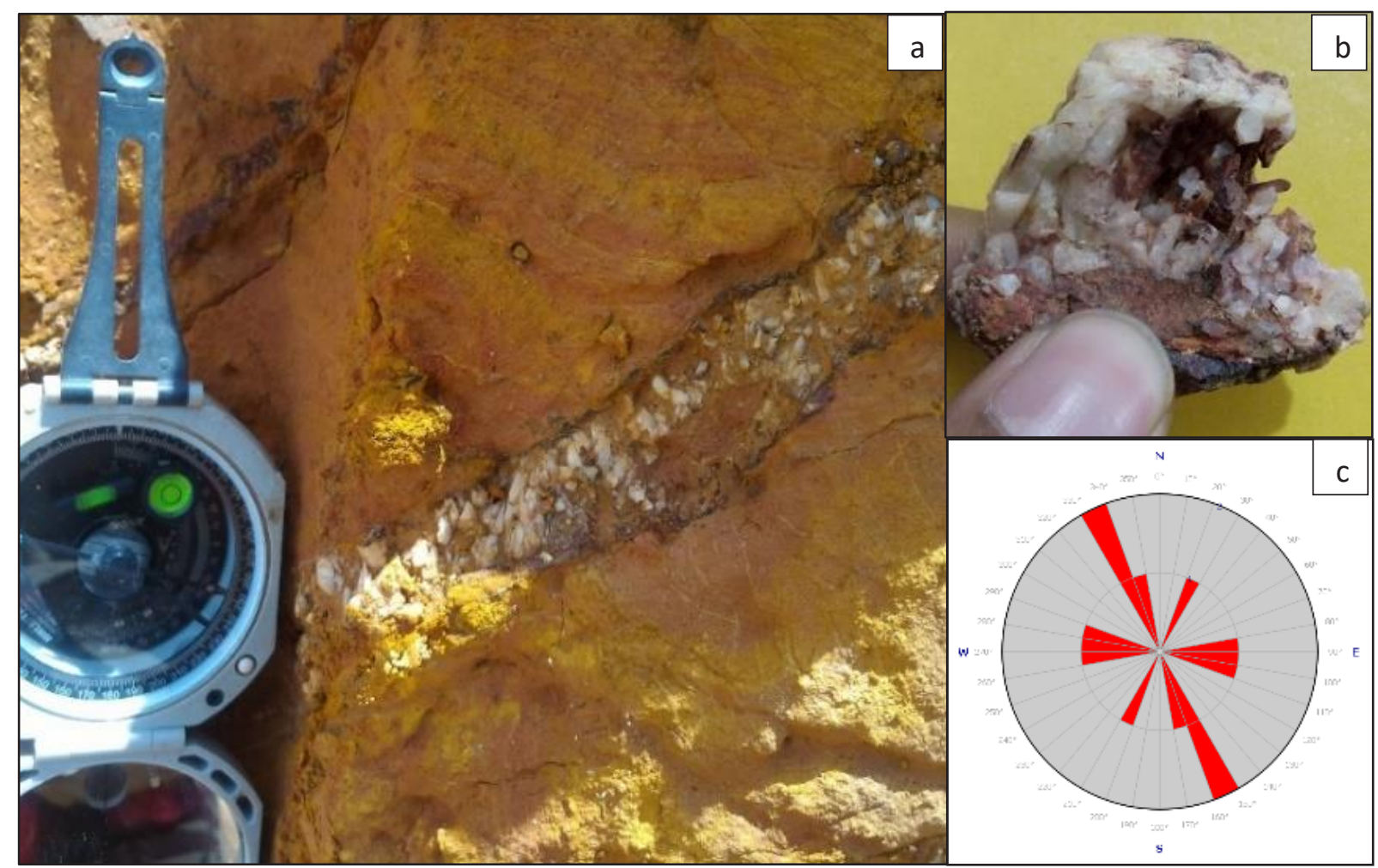

Gambar 11. (a) Urat kuarsa dan mineral oksida di tambang rakyat Pangapit.

(b) Tekstur comb pada urat kuarsa. (c) Diagram mawar yang menunjukan arah umum urat 


\section{MAKALAH ILMIAH}

\section{GEOKIMIA DAERAH PENELITAN}

Data geokimia berupa kadar unsur $\mathrm{Au}, \mathrm{Ag}$, $\mathrm{Cu}, \mathrm{Pb}, \mathrm{Zn}$, As dan Sb didapat dari uji AAS terhadap conto batuan dan urat kuarsa yang diambil dari daerah penelitian. Data selanjutnya diolah secara statistik untuk mengetahui conto mana saja yang memiliki nilai anomali emas. Selanjutnya letak conto dengan kadar emas tinggi di plot kedalam peta seperti yang dapat dilihat pada
Gambar 12. Selain penentuan conto dengan kadar emas tinggi, dilakukan juga analisis statistik dengan metode Spearman (Weir, 2018) untuk mengetahui asosiasi unsurnya. Unsur yang dijadikan acuan yaitu emas. Hasil analisis Spearman menunjukkan bahwa unsur emas hanya berasosiasi dengan unsur $\mathrm{Pb}$ dengan kekuatan sedang seperti yang dapat dilihat di Tabel 6.

Tabel 4. Mineral opak yang teridentifikasi dari hasil analisis mineragrafi urat kuarsa

\begin{tabular}{|c|c|c|c|c|c|}
\hline \multirow{2}{*}{ Kode Conto } & \multicolumn{5}{|c|}{ Mineral } \\
\hline & Pirit & Kalkopirit & Hematit & Goetit & Pirolusit \\
\hline \multicolumn{6}{|l|}{ SBS18M005RC9 } \\
\hline \multicolumn{6}{|l|}{ SBS18M009R } \\
\hline \multicolumn{6}{|l|}{ SBS18M023F } \\
\hline \multicolumn{6}{|l|}{ SBS18M029RC7 } \\
\hline \multicolumn{6}{|l|}{ SBS18M030R } \\
\hline \multicolumn{6}{|l|}{ SBS18M037R } \\
\hline SBS18M040RC4 & & & & & \\
\hline
\end{tabular}

Tabel 5. Paragenesis mineral logam di daerah penelitian

\begin{tabular}{lll}
\hline \multicolumn{1}{c}{ Mineral } & \multicolumn{1}{c}{ Tahap Pembentukan } \\
\cline { 2 - 3 } Pirit & \\
\hline Kalkopirit & \\
\hline Hematit & \\
\hline Goetit & \\
\hline Pirolusit &
\end{tabular}

Tabel 6. Koefisien korelasi Spearman antar unsur di daerah penelitian

\begin{tabular}{|l|r|l|l|l|l|l|l|l|l|}
\hline \multicolumn{7}{|c|}{ Korelasi Spearman } & Positif Kuat \\
\hline & $\mathrm{Au}$ & $\mathrm{Cu}$ & $\mathrm{Ag}$ & $\mathrm{Pb}$ & $\mathrm{Zn}$ & \multicolumn{1}{l|}{$\mathrm{As}$} & $\mathrm{Sb}$ & Positif Sedang \\
\hline $\mathrm{Au}$ & 1 & 0,01 & 0,07 & 0,45 & $-0,01$ & 0,33 & $-0,3$ & Positif Lemah \\
\hline $\mathrm{Cu}$ & & 1 & 0,15 & 0,07 & 0,43 & 0,16 & 0,08 & Positif Sangat Lemah \\
\hline $\mathrm{Ag}$ & & & 1 & 0,23 & 0,38 & 0,08 & 0,16 & Negatif Sangat Lemah \\
\hline $\mathrm{Pb}$ & & & & 1 & 0,35 & 0,22 & $-0,3$ & Negatif Lemah \\
\hline $\mathrm{Zn}$ & & & & & 1 & 0,15 & 0,01 & Negatif Sedang \\
\hline $\mathrm{As}$ & & & & & & 1 & 0 & Negatif Kuat \\
\hline $\mathrm{Sb}$ & & & & & & & 1 & Negatif Sangat Kuat \\
\hline
\end{tabular}




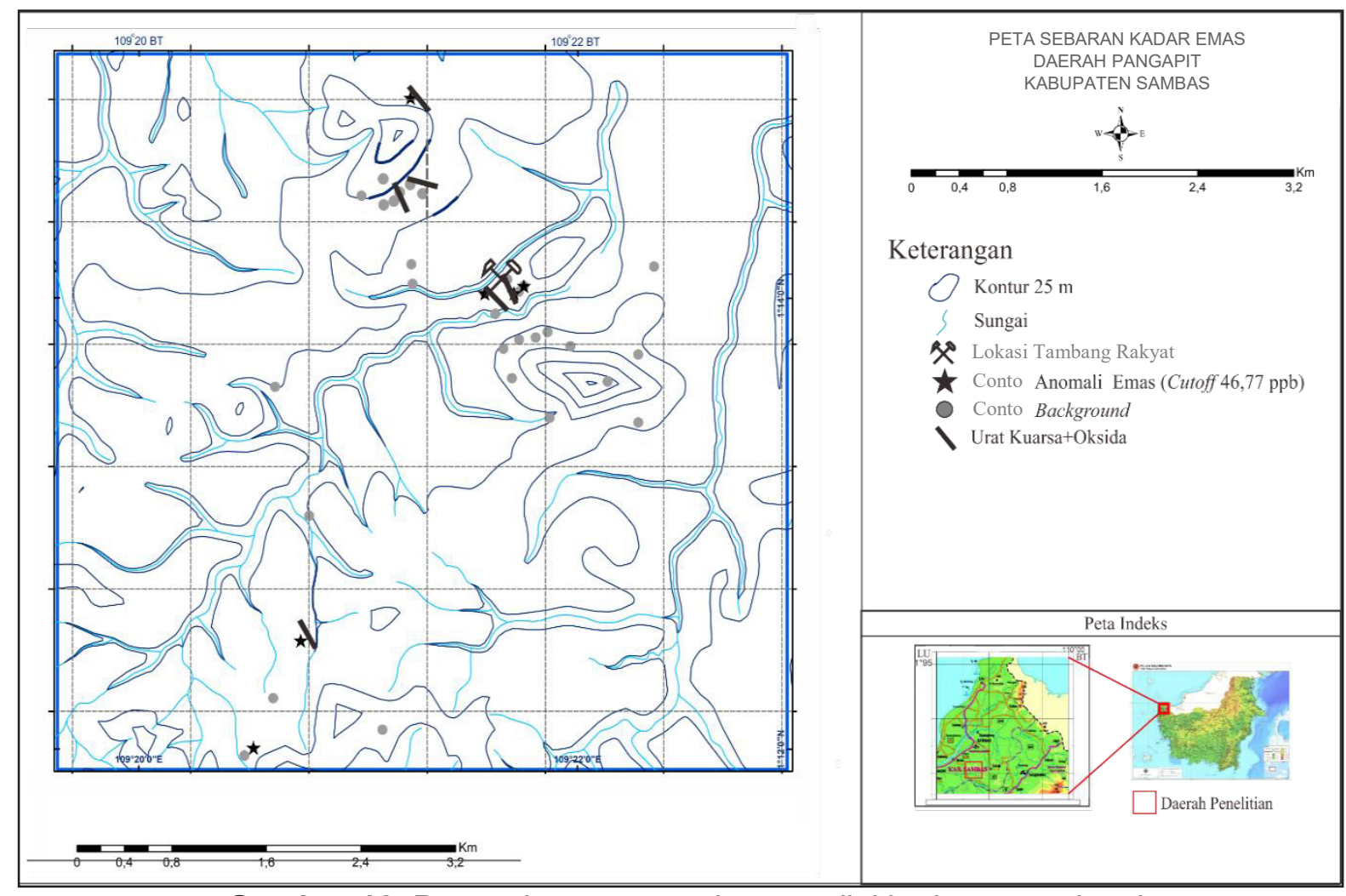

Gambar 12. Peta sebaran conto dengan nilai kadar emas tinggi

\section{DISKUSI DAN PEMBAHASAN}

Hasil analisis data geokimia menunjukkan bahwa conto dengan nilai kadar emas tinggi ditemukan terpusat di tambang rakyat Pangapit. Conto ini berupa batuan samping di sekitar urat kuarsa dan logam oksida yang memiliki tekstur comb sehingga disimpulkan bahwa Mineralisasi emas di daerah penelitian hadir berasosiasi dengan urat kuarsa dan logam oksida yang memiliki tekstur sisir. Uniknya, kadar emas di conto urat kuarsa dan logam oksida justru lebih rendah dibanding dengan kadar emas di batuan samping. Hal ini menunjukkan bahwa mineralisasi emas yang terjadi di tambang Pangapit juga dipengaruhi oleh proses pengayaan sekunder yang menyebabkan emas terkonsentrasi di batuan samping.

Hasil pemetaan alterasi menunjukkan bahwa daerah ini berasosiasi dengan zona serisit-illit. Hal tersebut mengindikasikan bahwa mineralisasi yang terjadi merupakan tipe epitermal sulfida rendah. Selanjutnya dilakukan studi literatur dengan membandingkan kondisi mineralisasi daerah penelitian dengan kondisi mineralisasi emas di daerah sekitarnya. Menurut Carlille dan Mitchel (1994) mineralisasi emas di daerah Kalimantan Barat dengan karakteristik tekstur, hostrock, dan mineralogi yang mirip dengan daerah penelitian diindikasikan merupakan tipe epitermal sulfida rendah. Tetapi masih diperlukan penelitian lebih lanjut guna mengetahui tipe mineralisasi sesungguhnya.

Mineralisasi emas terpusat di tambang rakyat Pangapit yang terletak di baratlaut Bukit Batubelah. Daerah ini mengalami alterasiserisit-illit secara intensif. Untuk mempermudah pemahaman mengenai hubungan antara pesebaran mineralisasi dengan zona alterasi digunakan model tipe mineralisasi epitermal sulfida rendah oleh Buchanan (1981). Menurut model ini zona alterasi di sekitar jalur fluida merupakan zona serisit-illit yang ditindih oleh zona alunit-kaolinit dan sinter opal. Tidak 
ditemukannya alunit dan sinter opal di daerah penelitian diduga diakibatkan telah terjadinya erosi secara intensif.

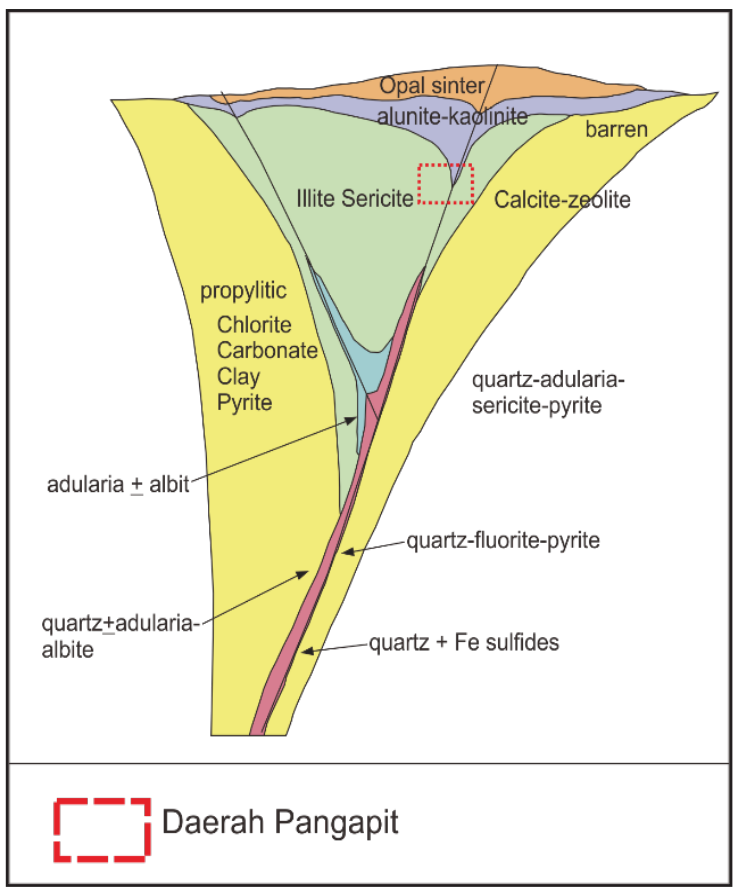

Gambar 13. Model tipe endapan epitermal sulfida rendah (modifikasi dari Buchanan, 1981)

Terdapat beberapa lokasi di daerah penelitian yang mengalami alterasi serisitillit secara intensif, seperti di tambangtambang Pangapit, kaki Bukit Kanyi dan kaki Bukit Praja Sekadau. Akan tetapi mineralisasi emas hanya dijumpai di tambang Pangapit. Hal ini mengindikasikan bahwa alterasi di daerah penelitian terjadi dalam beberapa tahap (minimal dua tahap) dan salah satunya terjadi bersamaan dengan mineralisasi emas. Dugaan ini semakin diperkuat oleh hasil pengamatan petrografi yang juga menunjukkan bahwa alterasi terjadi dalam dua tahap

Kondisi Satuan Basal yang tidak mengalami mineralisasi menandakan bahwa mineralisasi tidak terjadi bersamaan dengan alterasi klorit-kalsit-epidot tahap kedua, melainkan terjadi bersamaan dengan alterasi tahap pertama yaitu pasca Eosen. Dugaan ini diperkuat oleh data arah umum urat yaitu baratlaut. Apabila urat dianggap terbentuk akibat adanya fluida yang mengisi ruang yang timbul akibat rekahan regangan, maka bisa dianggap tegasan utama yang menghasilkan struktur urat adalah tegasan dengan arah utama baratlaut-tenggara. Arah ini sesuai dengan arah gerak Lempeng Lukonia pada Eosen hingga Miosen (Soeria-Atmadja dkk, 1999), waktu alterasi tahap pertama diduga terjadi.

Unsur emas di daerah penelitian hanya berasosiasi dengan unsur $\mathrm{Pb}$ dengan kekuatan sedang. Hal ini diinterpretasi dipengaruhi oleh kondisi daerah penelitian. Daerah penelitian telah mengalami oksidasi secara intensif yang ditunjukkan oleh kenampakan lapangan yang bewarna kemerahan dan banyaknya mineral logam oksida. Hadirnya banyak mineral lempung kaolinit menandakan bahwa daerah penelitian memiliki $\mathrm{pH}$ asam yang mendekati netral (Corbett dan Leach, 1998). Menurut Rose dkk (1979), pada kondisi permukaan oksidasi dan $\mathrm{pH}$ cenderung asam, unsur emas dan $\mathrm{Pb}$ sama-sama memiliki sifat susah bergerak (immobile). Kesamaan sifat mobilitas tersebutlah yang diduga menjadi penyebab mengapa emas hanya berasosiasi dengan unsur $\mathrm{Pb}$.

\section{KESIMPULAN}

Daerah penelitian mengalami alterasi yang terjadi dalam dua tahap. Alterasi tahap pertama terdiri dari alterasi kaolinit, serisitillit dan klorit-epidot-kalsit yang terjadi setelah Eosen dan sebelum Pliosen sedangkan alterasi tahap kedua terdiri dari alterasi kaolinit, serisit-illit dan klorit-epidotkalsit yang terjadi setelah Pleistosen. Alterasi pertama terjadi bersamaan dengan terjadinya mineralisasi emas di tambang rakyat Pangapit. Mineralisasi emas hadir berasosiasi dengan urat kuarsa dan mineral oksida yang memiliki tekstur comb. Berdasarkan data yang ada mineralisasi merupakan tipe epitermal sulfida rendah dengan asosiasi unsur $\mathrm{Au}-\mathrm{Pb}$. Tetapi masih perlu dilakukan penelitian lebih lanjut mengenai karakteristik urat kuarsa yang ada dengan metode fluida inklusi untuk mengetahui lebih jelas mengenai kondisi mineralisasi di daerah penelitian. 


\section{UCAPAN TERIMAKASIH}

Penulis mengucapkan terima kasih kepada Kepala Pusat Sumber Daya Mineral, Batubara dan Panas Bumi, Kepala Bidang Mineral, Kepala Subbidang Mineral Logam, Sekretaris Desa Madak, Kepala Dusun Pangapit serta semua pihak yang telah membantu dalam pembuatan tulisan ini.

\section{DAFTAR PUSTAKA}

Anonim, 2014, Laporan Penelitian Mineral Ikutan dan Unsur Tanah Jarang Daerah Bekas Tambang di Kabupaten Sambas, Provinsi Kalimantan Barat, Pusat Sumber Daya Geologi, Bandung.

Bandono dan Brahmantyo, Budi, 2006, Klasifikasi Bentuk Muka Bumi (Landform) untuk Pemetaan Geomorfologi pada Skala $1: 25.000$ dan Aplikasinya untuk Penataan Ruang, GEOAPLIKA.

Buchanan, L.J., 1981, Precious Metal Deposits Associated with Volcanic Environments in the Southwest, Arizona Geological Society Digest, 14.

Carlille, J. C. dan Mitchell, A. H. G., 1994, Magmatic Arcs and Associated Gold and Copper Mineralization in Indonesia, Journal of Geochemical Exploration 50, Melbourne.

Corbett, G. J. dan Leach, T. M., 1998, Southwest Pacific Rim Gold-Copper Systems: Structure, Alteration, and Mineralization: SEG Special Publication no. 6.
Rusmana, E. dan Pieters, P. E., 1993, Peta Geologi Lembar Sambar/Siluas, Kalimantan, Sekala $1: 250.000$, Pusat Penelitian dan Pengembangan Geologi, Bandung.

Gunter, B, 2011, The Exploration History, Geology, and Exploitation of the Buduk Gold Mine, West Kalimantan: an Example of a Small Gold Mine Operation in Kalimantan, Majalah Geologi Indonesia, 26, 173-190.

Morrison, K., 1997, Important Hydrothermal Minerals and their Significance. Geothermal and Minerals Service Division Limited.

Rose, A. W., Hawkes, H. E., dan Webb, J. S., 1979, Geochemistry in Mineral Exploration $2^{\text {nd }}$ Edition, Academic Press, London.

Soeria-Atmadja, R., Noeradi, D., dan Priadi, B., 1999, Cenozoic Magmatism in Kalimantan and its Related Geodynamic Evolution. Journal of Asia Earth Science 17:2545.

Van Zuidam, R. A., 1983, Guide to Geomorphology Aerial Photographic Interpretation and Mapping, Enshede, The Netherland.

Wicaksono, H. M. dkk., 2018, Laporan Akhir Eksplorasi Umum Emas daerah Pangapit dan sekitarnya Kabupaten Sambas Provinsi Kalimantan Barat, Pusat Sumber Daya Mineral, Batubara dan Panas Bumi, Badan Geologi, Bandung.

Weir, L., 2018, Spearman's Rank Correlation - Introduction di http://www.statstutor.ac.uk/resources /uploaded/spearmans.pdf, (diakses 16 Agustus 2018, 19.00).

\begin{tabular}{|ll|}
\hline Diterima & $:$ 26 Desember 2018 \\
Direvisi & $: 9$ Januari 2019 \\
Disetujui & $: 20$ Mei 2019 \\
\hline
\end{tabular}

